\title{
Distribution of Hypophysiotropic Thyrotropin-Releasing Hormone (TRH)-Synthesizing Neurons in the Hypothalamic Paraventricular Nucleus of the Mouse
}

\author{
Andrea Kádár ${ }^{1}$, Edith Sánchez ${ }^{2}$, Gábor Wittmann ${ }^{1,2}$, Praful S. Singru $^{2}$, Tamás Füzesi ${ }^{1}$, \\ Alessandro Marsili ${ }^{3}$, P. Reed Larsen ${ }^{3}$, Zsolt Liposits ${ }^{1,4}$, Ronald M. Lechan ${ }^{2,5}$, and Csaba \\ Fekete $^{1,2}$ \\ ${ }^{1}$ Department of Endocrine Neurobiology, Institute of Experimental Medicine, Hungarian Academy \\ of Sciences, Budapest, Hungary \\ 2 Tupper Research Institute and Department of Medicine, Division of Endocrinology, Diabetes, \\ and Metabolism, Tufts Medical Center, 800 Washington St, Boston, MA, 02111 \\ 3 Thyroid Section, Division of Endocrinology, Diabetes and Hypertension, Brigham and Women's \\ Hospital, Boston, MA \\ 4 Department of Neuroscience, Faculty of Information Technology, Pázmány Péter Catholic \\ University, Budapest, Hungary \\ ${ }^{5}$ Department of Neuroscience, Tufts University School of Medicine, Boston, Massachusetts \\ 02111
}

\section{Abstract}

Hypophysiotropic thyrotropin-releasing hormone (TRH) neurons, the central regulators of the hypothalamus-pituitary-thyroid axis, are located in the hypothalamic paraventricular nucleus (PVN) in a partly overlapping distribution with non-hypophysiotropic TRH neurons. The distribution of hypophysiotropic TRH neurons in the rat PVN is well understood, but the localization of these neurons is unknown in mice. To determine the distribution and phenotype of hypophysiotropic TRH neurons in mice, double- and triple-labeling experiments were performed on sections of intact mice, and mice treated intravenously and intraperitonially with the retrograde tracer Fluoro-Gold. TRH neurons were located in all parts of the PVN except the periventricular zone. Hypophysiotropic TRH neurons were observed only at the mid level of the PVN, primarily in the compact part. In the this part of the PVN, TRH-neurons were intermingled with oxytocin and vasopressin neurons, but based on their size, the TRH neurons were parvocellular and did not contain magnocellular neuropeptides. Co-localization of TRH and CART were observed only in areas where hypophysiotropic TRH neurons were located. In accordance with the morphological observations, hypothyroidism increased TRH mRNA content of neurons only at the mid level of the PVN.

These data demonstrate that the distribution of hypophysiotropic TRH neurons in mice is vastly different from the pattern in rats, with a dominant occurrence of these neurosecretory cells in the compact part and adjacent regions at the mid level of the PVN. Furthermore, our data demonstrate that the organization of the PVN is markedly different in mice and rats.

Corresponding Author: Csaba Fekete M.D., Ph. D. Department of Endocrine Neurobiology Institute of Experimental Medicine Hungarian Academy of Sciences 43 Szigony St Budapest, Hungary 1083 Phone: 36-1-210-9947 Fax: 36-1-210-9961 feketecs@koki.hu. 


\section{Introduction}

Thyrotropin-releasing hormone (TRH) is a tripeptide-amide widely synthesized throughout the central nervous system (CNS) (Lechan and Fekete, 2006). Although involved in the regulation of many physiological functions, its best known action is the central regulation of the hypothalamic-pituitary-thyroid (HPT) axis (Reichlin, 1989). In rats, the so-called "hypophysiotropic" TRH neurons that regulate the TSH secretion of anterior pituitary, are located in the hypothalamic paraventricular nucleus (PVN) (Fekete et al., 2000; Ishikawa et al., 1988; Merchenthaler and Liposits, 1994; Simmons and Swanson, 2009), a triangular nucleus located at the dorsal margin of the third ventricle in all mammalian species. The PVN can be divided into two, main divisions dictated by the size of their neurons, namely magnocellular and parvocellular divisions (Swanson and Kuypers, 1980). The parvocellular division can be further divided into 6 subdivisions, the anterior, periventricular, medial, ventral, lateral and dorsal parvocellular subdivisions (Swanson and Kuypers, 1980). All parvocellular subdivisions contain at least some TRH-synthesizing neurons (Lechan and Jackson, 1982) but in rats, only TRH neurons residing in the periventricular and medial parvocellular subdivisions terminate in the median eminence (Fekete et al., 2000; Ishikawa et al., 1988; Merchenthaler and Liposits, 1994) where TRH is released onto the portal capillary system for conveyance to the anterior pituitary (Fekete and Lechan, 2007).

Although the location of hypophysiotropic TRH neurons is precisely determined in rats, limited information is currently available about the distribution of these neurons in mice. Given the increasing utility of transgenic mouse models in elucidating the physiology and neurobiology of neuronal systems in the CNS, it is important to determine the distribution of hypophysiotropic TRH neurons in the mouse PVN. Accordingly, taking advantage of the knowledge that the median eminence lies outside of the blood-brain barrier (Weindl, 1973), we mapped the distribution of the hypophysiotropic TRH neurons in the hypothalamus of mice by retrograde neuronal tracing following the administration of Fluoro-Gold into the systemic circulation. In addition, we matched the distribution pattern of retrogradely labeled hypophysiotropic neurons with the map of paraventricular neurons responding with increased TRH gene expression to hypothyroidism (Lechan and Kakucska, 1992; Segerson et al., 1987).

\section{Materials and methods}

\section{Animals}

The experiments were carried out on adult, male, CD1 and C57B6 mice weighing 28-30g. The animals were housed under standard environmental conditions (light between 6:00 A.M. and 6:00 P.M., temperature $22^{\circ} \mathrm{C}$, chow and water ad libitum). All experimental protocols were reviewed and approved by the Animal Welfare Committees at the Institute of Experimental Medicine of the Hungarian Academy of Sciences, Budapest, Hungary, Tufts Medical Center and the Brigham and Women's Hospital, Boston, MA.

\section{Tissue preparation}

To detect hypophysiotropic neurons, 4 animals received intravenous injection of FluoroGold $(15 \mu \mathrm{g} / \mathrm{g}$ BW in $100 \mu \mathrm{l} 0.9 \%$ saline, Fluorochrome. Llc., CO USA) and 2 days later were injected intraperitoneally with Fluoro-Gold $(15 \mu \mathrm{g} / \mathrm{g}$ BW in $100 \mu \mathrm{l} 0.9 \%$ saline, Fluorochrome. Llc., CO USA). Five days later, the deeply anesthetized animals (ketamine: $50 \mu \mathrm{g} / \mathrm{g}$; xylazine: $10 \mu \mathrm{g} / \mathrm{g}$ body weight, i.p.) were intracerebroventricularly treated with colchicine $(1 \mu \mathrm{g} / \mathrm{g} \mathrm{BW})$ by injection through a $26 \mathrm{~g}$ needle placed into the lateral ventricle under stereotaxic control (coordinates from Bregma: antero-posterior $-0.2 \mathrm{~mm}$, lateral $1 \mathrm{~mm}$, dorsoventral $-2.5 \mathrm{~mm}$ ) (Paxinos and Watson, 1998). Control animals were not injected 
with Fluoro-Gold, but received treatment with colchicine as described above. Twenty hours after the colchicine treatment, the animals were deeply anesthetized with ketamine-xylazine and perfused through the ascending aorta with $10 \mathrm{ml}$ PBS (pH 7.4), followed by $30 \mathrm{ml} 1 \%$ acrolein/3\% paraformaldehyde (PFA) in PBS, and finally $20 \mathrm{ml} \mathrm{3 \%} \mathrm{PFA} \mathrm{in} \mathrm{PBS.} \mathrm{The} \mathrm{brains}$ were removed and were cryoprotected in $20 \%$ sucrose in PBS at $4^{\circ} \mathrm{C}$ overnight, then frozen on dry ice. Twenty-five micrometer thick coronal sections through the rostro-caudal extent of the PVN were cut on freezing microtome (Leica Microsystems, Vienna, Austria), collected in four identical sets in cryoprotective solution (30\% ethylene-glycol; $25 \%$ glycerol; $0.05 \mathrm{M}$ phosphate buffer) and stored at $-20^{\circ} \mathrm{C}$ until used.

A separate group of mice $(n=5)$ were made hypothyroid by the addition of $0.1 \%$ methimazole and $1 \% \mathrm{NaClO}_{4}\left(\mathrm{MMI} / \mathrm{ClO}_{4}\right)$ to the drinking water for 4-5 weeks (Peeters et al., 2001), and compared to control, euthyroid animals $(\mathrm{n}=5)$. Under sodium pentobarbital anesthesia, blood was collected from the inferior vena cava and then, the animals were perfused transcardially with $10 \mathrm{ml} 0.01 \mathrm{M}$ diethylpyrocarbonate (DEPC)-treated PBS, $\mathrm{pH}$ 7.4, containing 15,000 U/liter heparin sulfate followed by $40 \mathrm{ml} 4 \%$ paraformaldehyde in DEPC-treated PBS. The brains were removed and postfixed by immersion in the same fixative for $4 \mathrm{~h}$ at room temperature. Tissue blocks containing the hypothalamus were cryoprotected in $25 \%$ sucrose in DEPC-treated PBS at $4^{\circ} \mathrm{C}$ overnight, then snap frozen on dry ice. Serial $18 \mu \mathrm{m}$ thick coronal sections through the rostro-caudal extent of the PVN were cut on a cryostat (Leica CM3050 S, Leica Microsystems, Nussloch GmbH, Germany) and adhered to Superfrost/Plus glass slides (Fisher Scientific Co., Pittsburgh, PA) to obtain four sets of slides, each set containing every fourth section through the PVN. The tissue sections were desiccated overnight at $42^{\circ} \mathrm{C}$ and stored at $-80^{\circ} \mathrm{C}$ until prepared for in situ hybridization histochemistry.

\section{Single-, double- and triple labeling immunofluorescence}

The sections were pretreated with $1 \%$ sodium borohydride in distilled water for $30 \mathrm{~min}$, followed by $0.5 \%$ Triton $\mathrm{X}-100$ and $0.5 \% \mathrm{H}_{2} \mathrm{O}_{2}$ in $0.01 \mathrm{M}$ PBS for 15 min. Nonspecific antibody binding was blocked with $10 \%$ normal horse serum (NHS) in PBS for $15 \mathrm{~min}$. The sections were then processed for single-, double- and triple labeling immunocytochemistry as described below.

i. Single labeling immunofluorescence for $\mathbf{T R H}$-The sections were incubated in sheep anti-TRH serum (1:4000, generated in our laboratory (Wittmann et al., 2009)) in serum diluent (2\% NHS, $0.2 \%$ PhotoFlo, $0.2 \%$ sodium azide in PBS) for two days at $4{ }^{\circ} \mathrm{C}$. Then, the sections were incubated in biotinylated donkey anti-sheep $\operatorname{IgG}$ (1:500, Jackson Immunoresearch Laboratories, PA, USA) for two hours at room temperature followed by incubation in Avidin-Biotin-Peroxidase complex (1:1000 Vector Laboratories, Inc., CA, USA) in $0.05 \mathrm{M}$ Tris buffer (TB) (pH 7.6) for 1 hour. The immunolabeling was visualized by $0.05 \% \mathrm{DAB} / 0.15 \% \mathrm{Ni}$-ammonium-sulfate $/ 0.005 \% \mathrm{H}_{2} \mathrm{O}_{2}$ in $0.05 \mathrm{M}$ TB.

\section{ii. Triple labeling immunofluorescence for Fluoro-Gold, TRH and vasopressin} (AVP)-The sections were incubated in a mixture of rabbit anti-FluoroGold serum (1: 24,000, Chemicon International Inc.), sheep anti-TRH serum (1:4000) and mouse anti-AVPneurophysin (AVP-NP) antibody (1:500, PS-41; gift from Dr H.Gainer NIH, Bethesda, MD, US) in serum diluent for two days at $4^{\circ} \mathrm{C}$. Then, the sections were incubated in the following mixture of secondary antibodies: biotinylated donkey anti-rabbit IgG (1:500, Jackson Immunoresearch Laboratories, PA, USA), Alexa 555-conjugated donkey anti-sheep IgG (1:500, Invitrogen, Corp., CA, USA) and FITC-conjugated donkey anti-mouse IgG (1:50, Jackson Immunoresearch) in serum diluent at room temperature for 2 hours, followed by incubation in Avidin-Biotin-Peroxidase complex (Vector Laboratories, Inc., CA, USA) at 
1:1,000 dilution in $0.05 \mathrm{M}$ TB for 1 hour. The Fluoro-Gold immunoreactive product was amplified with biotinylated tyramide using the TSA amplification kit (Perkin Elmer Life and Analytical Sciences, Waltham, MA) according to the manufacturers instructions, followed by incubation in Cy5-streptavidin (1:200, Jackson ImmunoResearch Laboratories, PA, USA) diluted in serum diluent, for $1.5 \mathrm{~h}$.

iii. Triple labeling immunfluorescence for Fluoro-Gold, TRH and oxytocin (OT) -The triple-labeling was performed as described above, except the anti-AVP-NP antibody was replaced with mouse anti-OT-NP antibody (1:500, PS-38; 1/1000, kindly provided by Dr. Sharon Key, Public Health Service, NIH, Bethesda, MD..

iv. Double labeling immunofluorescence for TRH and CART-The sections were incubated in sheep anti-TRH serum (1:4000) and mouse anti-CART antibody (1:1500, gift from Dr. Jes Thorn Clausen, Novo Nordisk A/S, Bagsvaerd, Denmark) for 2 days at $4^{\circ} \mathrm{C}$. Then, the sections were treated with a mixture of Alexa 555-conjugated donkey anti-sheep $\operatorname{IgG}(1: 500$, Invitrogen, Corp., CA, USA) and FITC-conjugated donkey anti-mouse IgG (1:300, Jackson ImmunoResearch Laboratories, PA, USA) for 2 hours at room temperature.

\section{Antibody specificity}

Sheep antiserum against TRH (code 08W2) was raised in our laboratory against TRH conjugated to BSA with acrolein. The generation and characterization of the antiserum was described elsewhere (Wittmann et al., 2009) The specificity of the antiserum for immunocytochemistry was tested by preabsorption with TRH (Bachem) at $80 \mu \mathrm{g} / \mathrm{ml}$ concentration, which resulted in the complete loss of axonal and perikaryal staining. The distribution of the immunoreactive elements was the same as previously described (Lechan and Jackson, 1982). CART immunoreactivity was visualized using a mouse monoclonal antibody raised against purified recombinant CART(41-89) (Thim et al., 1998).

Recombinant CART(41-89) was conjugated to ovalbumin using carbodiimide as a carrier. The specifity of CART antiserum was tested by the combination of single-labeling immunocytochemistry for CART and in situ hybridization using antisense RNA probes directed against the rat CART cDNA (bp 226-411; GenBank accession number U10071). The distribution of CART-IR cells in colchicine-treated material exactly overlapped that described for the in situ hybridization, suggesting that all cells constitutively expressing CART are visualized (Vrang et al., 1999).

For monoclonal anti-OT-NP and anti-AVP-NP antibodies, BALB/c mice were immunized intraperitoneally with acid-soluble extracts of rat neurointermediate lobes in complete Freund $\sim \mathrm{s}$ adjuvant. The specifity of these antibodies was tested by immunohistochemistry and solid and liquid phase radioimmunoassay. With light-microscopic immunohistochemistry, both anti-OT-NP and anti-AVP-NP stained exclusively the posterior pituitary, and the paraventricular and supraoptic nuclei of rat hypothalamus. The radioimmunoassay demonstrated that anti-AVP IgG (PS-41) is highly specific for the complex of AVP-NP and does not cross-react with OT-NP, whereas anti-OT-NP IgG (PS-38) reacts with OT-NP exclusively. Additionally, peptides synthesized in the rat neurointermediate lobe, i.e., dynorphin A and dynorphin B (100 pmol/tube), $\beta$-endorphin (100 pmol/tube), $\alpha$-melanocyte-stimulating hormone ( $\alpha$ - MSH, $1000 \mathrm{pmol} /$ tube), and angiotensin II (10,000 pmol/tube), did not affect antibody binding (Ben-Barak et al., 1985).

Rabbit antiserum raised against Fluoro-Gold did not give any staining on sections originating from mice without Fluoro-Gold treatment. Details of the used antisera are summarized in Table 1. 


\section{Nissl counterstaining}

Sections mounted on gelatine-coated slides were dehydrated with ascending series of ethanol, treated with xylene for $5 \mathrm{~min}$ and rehydrated in descending series of ethanol and in MilliQ water. Then, the sections were treated with 1\% cresyl-violet solution for $3 \mathrm{~min}$ followed by differentiation in acetic acid in 100\% ethanol (at 1:50,000 dilution) for $5 \mathrm{sec}$. Following dehydration in ascending series of ethanol, the sections were treated with xylene and coverslipped using DPX Mounting medium (Sigma-Aldrich, Inc., USA).

\section{In situ hybridization histochemistry for TRH mRNA}

Every fourth section of the PVN was hybridized with a 741 base (corresponding to the 106-846 nucleotids of the mouse TRH mRNA; BC053493) single stranded $\left[{ }^{35}\right.$ S]UTP labeled cRNA probe for mouse TRH following methods as previously described (Fekete et al., 2001). In vitro transcription was performed using SP6/T7 systems (Roche) and $\left[{ }^{35} \mathrm{~S}\right] \alpha-$ UTP (1000 Ci/mmol; New England Nuclear, Boston, MA, USA). The hybridization was performed under plastic coverslips in a buffer containing 50\% formamide, a 2-fold concentration of standard sodium citrate (2XSSC), $10 \%$ dextran sulfate, $0.5 \%$ sodium dodecyl sulfate, $250 \mu \mathrm{g} / \mathrm{ml}$ denatured salmon sperm DNA, and $5 \times 10^{5} \mathrm{cpm}$ of radiolabeled probe for $16 \mathrm{~h}$ at $56^{\circ} \mathrm{C}$. Slides were dipped into Kodak NTB autoradiography emulsion (Eastman Kodak, Rochester, N.Y.) diluted 1:1 in distilled water, and the autoradiograms developed after 4 days of exposure at $4^{\circ} \mathrm{C}$.

\section{Image analyses}

The sections were covered with Vectashield mounting medium containing DAPI (Vector). Images were taken using a Biorad Radiance 2100 confocal laser-scanning microscope (BioRad Laboratories, Hemel Hempstead, UK) with 20X, 40X and 60X objectives using LaserSharp program and the following lasers: FITC 488nm, Cy3 543nm and dicroic/ emission filters: FITC 560nm/500-530nm, Cy3 560-625nm. Image analysis was performed using ImageJ and LaserVox software. The maps were drawn in CorelDRAW11 software. The largest diameter of the perikarya of randomly selected $50 \mathrm{TRH}-$ and 50 vasopressincontaining neurons and 100-100 randomly selected Nissl stained neurons located in the compact part of the PVN or in the midlevel medial part of the PVN, respectively, from each animal $(n=3)$ was measured with ImageJ software (http://rsbweb.nih.gov/ij/). Images of blue DAPI signal were overlaid with the fluorescent images of the immunostainings to facilitate the differentiation between magnocellular and parvocellular divisions. The composite images were prepared with the Adobe Photoshop CS program. The contrast and brightness was adjusted in this software.

As we observed that the organization of the mouse PVN is highly different from the organization of the PVN in rats, instead of using the nomenclature of the mouse brain atlas by Paxinos and Franklin (Paxinos and Franklin, 2001) that was adapted from the rat brain nomenclature, we have divided the PVN into five parts (Fig. 1). These parts are as follows:

compact $=$ a cell dense region in the mid level of the PVN that contains both magnoand parvocellular cells (Fig. 1B)

periventricular $=3-5$ cell wide zone adjacent to the third ventricle (Fig. 1A-C)

anterior $=$ cranial to the compact part (Fig. 1A)

midlevel medial $=$ located between the compact part and the periventricular zone at the mid level of the PVN (Fig. 1B)

posterior $=$ located caudal to the compact part (Fig. 1C) 
In situ hybridization autoradiograms were visualized under darkfield illumination using a COHU 4910 video camera (COHU, Inc., San Diego, CA). The images were captured with a color PCI frame grabber board (Scion Corporation, Frederick, MD) and analyzed with a Macintosh G4 computer using Scion Image. Background density points were removed by thresholding the image and integrated density values (density $\times$ area) of hybridized neurons on each side of the PVN were measured in two consecutive sections for the anterior, mid and caudal levels of the PVN. Nonlinearity of radioactivity in the emulsion was evaluated by comparing density values with a calibration curve created from autoradiograms of known dilutions of the radiolabeled probes immobilized on glass slides in $2 \%$ gelatin fixed with $4 \%$ formaldehyde and exposed and developed simultaneously with the in situ hybridization autoradiograms.

\section{Hormone measurements}

Serum T4 levels were measured using the COAT-A-COUNT total $\mathrm{T}_{4}$ kit (DPC, Los Angeles, CA) following the manufacturer's instructions with a mouse $\mathrm{T}_{4}$ standard curve prepared in charcoal-stripped mouse serum. TSH was determined using the rat TSH ${ }^{125} \mathrm{I}$ Biotrak Assay System from Amersham Biosciences (Piscataway, NJ). A standard curve was generated by the serial dilution of hypothyroid mouse serum with sera from male C57/B16 mice given $1 \mu \mathrm{g} /$ day of L-T3 for 5 days to suppress endogenous TSH secretion (low-TSH mouse serum). TSH concentrations ( $\mathrm{ng} / \mathrm{ml})$ were extrapolated from the intercept of the high TSH mouse serum with the purified rat TSH standard curve supplied by the manufacturer with correction for the small difference in the nonspecific binding obtained with serum vs. that obtained with the assay buffer. Samples from hypothyroid mice were also diluted with low-TSH mouse serum to fall within the linear range of the standard curve.

\section{Results}

\section{Distribution of TRH-IR neurons in the PVN}

TRH immunoreactive neurons were observed in all parts of the PVN except in the periventricular zone (Fig. 2). Moving from rostral to caudal portions of the PVN, TRHcontaining neurons were observed in all three levels (anterior, mid and posterior levels), but the density was the highest at the anterior and mid levels of the PVN (Fig. 2A, C). The largest number of the detected TRH neurons was observed in the compact part of the PVN (Fig. 2C). The shape and size of the TRH neurons located in the compact and in the other parts of the PVN were similar (size of TRH neurons in midlevel medial part of the PVN $v s$. compact part $(\mu \mathrm{m}): 12.15 \pm 0.05$ vs. $12.26 \pm 0.02 ; \mathrm{P}=0.31)$.

\section{Distribution of hypophysiotropic TRH neurons in the PVN}

Fluoro-Gold accumulating in neuronal perikarya was readily visualized and had an inhomogeneous and punctuate appearance (Fig. 3B). Although the anterior part of the PVN contained a large number of TRH neurons, only very few were co-labeled with Fluoro-Gold (Fig. 3C; 4A; 5A). Similarly, none of the TRH neurons in the posterior part of the PVN contained Fluro-Gold (Fig. 3D; 4G; 5G). Most double-labeled neurons were located in the compact part of the PVN (Fig. 3A, B; 4B-F; 5B-F).

\section{Comparison between the distribution of hypophysiotropic TRH neurons and vasopressin and oxytocin neurons in the PVN}

AVP and OT neurons were observed primarily in the compact part of the PVN, although scattered cells were also observed in the midlevel medial part of PVN (Figs. 4-6). The size of of magnocellular AVP neurons $(16.4 \pm 0.1 \mu \mathrm{m})$ was significantly larger than the size of the TRH neurons $(\mathrm{p}<0.001)$. Hypophysiotropic TRH neurons containing both Fluoro-Gold- 
and TRH-immunoreactivity were also primarily observed in the compact part of the PVN, and were intermingled with AVP and OT neurons (Fig. 4-6). No co-localization of TRH and AVP or OT was observed in this region (Fig. 4-6). In addition, no co-localization was observed in any other region of the PVN where OT and AVP were identified.

To further clarify the presence of magnocellular and parvocellular cells in the compact and midlevel medial parts of the PVN, histograms of the cell sizes were created using criteria for magnocellular neurons as $\geq 14 \mu \mathrm{m}$ and parvocellular as $<14 \mu \mathrm{m}$. In the compact part, an approximately equal number of cells had less than $14 \mu \mathrm{m}$ diameter $(49.3 \pm 0.9 \%)$ or $14 \mu \mathrm{m}$ or greater diameter $(50.7 \pm 0.9 \%)$. In the midlevel medial part of PVN, the vast majority of cells were smaller than $14 \mu \mathrm{m}(96.0 \pm 1.2 \%)$ and only scattered cells had diameter $14 \mu \mathrm{m}$ or greater $(4.4 \pm 1.2 \%)$. The distribution of the cell size of neurons located in the midlevel medial part of the PVN and at the compact part of the PVN is illustrated in Fig 7.

\section{Co-localization of CART and TRH in the neurons of the PVN}

The localization of neurons co-synthesizng CART and TRH in the PVN of mice was similar to that of the TRH neurons accumulating Fluoro-Gold. Numerous CART-TRH doublelabeled neurons were observed at the mid level of PVN in the compact part (Fig. 8A, D; 9BF). Colocalization of CART and TRH was not detected in the posterior part of PVN, and only a few double-labeled cells were present in the anterior part (Fig. 9A, G). Colocalization of the two peptides was also detected in the axon terminals of the median eminence (Fig. 8C).

\section{Effect of hypothyroidism on TRH gene expression in the PVN}

In control mice, TRH mRNA was readily visualized throughout the rostro-caudal extent of the PVN organized in a distribution identical to that described above for TRHimmunoreactivity (Fig. 10A-C). TRH mRNA hybridization signal was fairly uniform throughout the PVN including anterior-, mid- and posterior-levels (Fig. 10A-C). Hypothyroidism resulted in a marked increase $(\mathrm{P}<0.001)$ in TRH mRNA expression in neurons occupying the mid-portion of the PVN (Fig. 10E, G), but had no effect $(\mathrm{P}>0.05)$ on TRH mRNA expression in the anterior (Fig. 10D, G) and posterior levels (Fig. 10F, G). Serum T4 concentrations were $<0.5 \mu \mathrm{g} / \mathrm{dl}$ and TSH $86 \pm 8.8 \mathrm{ng} / \mathrm{ml}$ in hypothyroid mice compared to euthyroid control values of $2.6 \pm 0.1 \mu \mathrm{g} / \mathrm{dl}$ and $4.0 \pm 0.7 \mathrm{ng} / \mathrm{ml}$, respectively.

\section{Discussion}

TRH neurons were detected in all parts of the PVN of mice except the periventricular zone. This distribution markedly differs from that observed in the rat brain in which only a few TRH neurons can be identified in the magnocellular division (Lechan and Jackson, 1982). In addition, TRH neurons are completely absent from the periventricular zone in mice, where numerous TRH neurons reside in the rat PVN (Lechan and Jackson, 1982).

The predominant localization of TRH neurons in the compact part of the PVN in mice raised the question whether these neurons have parvocellular or magnocellular phenotype. To address this issue, evidence for co-localization of vasopressin or oxytocin with TRH was studied by fluorescent immunocytochemistry. Although TRH-IR neurons were intermingled with vasopressin- and oxytocin-IR neurons in the compact part of the PVN, co-localization of TRH with either of these two magnocellular peptides was not observed. In accordance with this finding, morphometric analysis of TRH- and vasopressin-IR neurons demonstrated that TRH neurons located in the magnocellular division are significantly smaller than the magnocellular, vasopressin producing neurons and not significantly different in size from TRH neurons residing in other parts of the PVN. This analysis indicates that TRH neurons 
in all regions of the PVN have a parvocellular phenotype. As these parvocellular neurons are intermingled with magnocellular vasopressin and oxytocin neurons in the mouse brain in region what would be considered the posterior magnocellular division in the rat, a major deviation in the structural organization of this nucleus is suggested compared to the rat. This observation is further supported by the morphometric analyses of the Nissl stained preparations that showed that a similar number of parvo- and magnocellular cells can be found in the compact part of the mouse PVN. Therefore, we suggest that in the mouse, this part of the PVN be termed the "compact part", based on the high density of cells in this part of the PVN, instead of using the nomenclature adopted from rat studies. Further studies will be necessary to determine the borders of the subnuclei of the other parts of the mouse PVN.

Further distinguishing the unique anatomy of the PVN in the mouse compared to the rat is the observation that Fluoro-Gold containing hypophysiotropic TRH neurons were detected only at the mid level of the PVN. In particular, TRH neurons in the posterior part of the PVN that are distinctly hypophysiotropic in the rat (Fekete and Lechan, 2007; Ishikawa et al., 1988; Merchenthaler and Liposits, 1994; Simmons and Swanson, 2009), did not concentrate Fluoro-Gold in the mouse. Furthermore, the majority of hypophysiotropic TRH neurons at the mid level of PVN were concentrated in the compact part, with fewer neurons organized in the adjacent midlevel medial part of PVN. Similar to the rat brain (Ishikawa et al., 1988; Kawano et al., 1991; Merchenthaler and Liposits, 1994; Simmons and Swanson, 2009), however, was the absence of Fluoro-Gold in TRH neurons residing in the anterior part of the PVN, establishing the non-hypophysiotropic nature of this group of neurons. In addition, similar to the rat (Fekete et al., 2000), hypophysiotropic TRH neurons in the mouse also co-express CART which is present in both the perikarya in the mid level of the PVN neurons and in their axon terminals innervating the median eminence. Colocalization was only rarely observed in the anterior and posterior parts of the PVN. Similar observations were published earlier by Broberger et al. (Broberger, 1999).

As confirmation of the immunocytochemical and tracing studies, hypothyroidism resulted in increased TRH gene expression in the compact part and in the midlevel medial part of the PVN in the mouse. In contrast, hypothyroidism had no effect on the TRH gene expression in the anterior and posterior parts of the PVN. It is worth emphasizing, that this observation is definitely different from the phenomenon seen in the rat in which hypothyroidism increases TRH mRNA throughout the medial and periventricular parvocellular subdivisions of the PVN with a particularly robust response in the most caudal aspect of the PVN (Lechan and Kakucska, 1992).

The studies indicate that the organization of PVN and in particular, the distribution of hypophysiotropic TRH neurons, is markedly different in mice and rats. Accordingly, targeted physiological and molecular studies of hypophysiotropic TRH neurons in mice are supposed to take into consideration that these neurons are located in the compact part and in the neighboring region in the mid level of the PVN and absent from the anterior and posterior parts of the PVN.

\section{Acknowledgments}

This work was supported by grants from the NIH (DK37021, DK 36256, RDK070600 and TW007834) and OTKA K-81845.

\section{References}

Ben-Barak Y, Russell JT, Whitnall MH, Ozato K, Gainer H. Neurophysin in the hypothalamoneurohypophysial system. I. Production and characterization of monoclonal antibodies. J Neurosci. 1985; 5(1):81-97. [PubMed: 3880813] 
Broberger C. Hypothalamic cocaine- and amphetamine-regulated transcript (CART) neurons: histochemical relationship to thyrotropin-releasing hormone, melanin-concentrating hormone, orexin/hypocretin and neuropeptide Y. Brain Res. 1999; 848(1-2):101-113. [PubMed: 10612702]

Fekete C, Kelly J, Mihaly E, Sarkar S, Rand WM, Legradi G, Emerson CH, Lechan RM. Neuropeptide Y has a central inhibitory action on the hypothalamic-pituitary-thyroid axis. Endocrinology. 2001; 142(6):2606-2613. [PubMed: 11356711]

Fekete C, Lechan RM. Negative feedback regulation of hypophysiotropic thyrotropin-releasing hormone (TRH) synthesizing neurons: role of neuronal afferents and type 2 deiodinase. Front Neuroendocrinol. 2007; 28(2-3):97-114. [PubMed: 17588648]

Fekete C, Mihaly E, Luo LG, Kelly J, Clausen JT, Mao Q, Rand WM, Moss LG, Kuhar M, Emerson $\mathrm{CH}$, Jackson IM, Lechan RM. Association of cocaine- and amphetamine-regulated transcriptimmunoreactive elements with thyrotropin-releasing hormone-synthesizing neurons in the hypothalamic paraventricular nucleus and its role in the regulation of the hypothalamic-pituitarythyroid axis during fasting. J Neurosci. 2000; 20(24):9224-9234. [PubMed: 11125000]

Ishikawa K, Taniguchi Y, Inoue K, Kurosumi K, Suzuki M. Immunocytochemical delineation of thyrotrophic area: origin of thyrotropin-releasing hormone in the median eminence. Neuroendocrinology. 1988; 47(5):384-388. [PubMed: 3135505]

Kawano H, Tsuruo Y, Bando H, Daikoku S. Hypophysiotrophic TRH-producing neurons identified by combining immunohistochemistry for pro-TRH and retrograde tracing. J Comp Neurol. 1991; 307(4):531-538. [PubMed: 1907979]

Lechan RM, Fekete C. The TRH neuron: a hypothalamic integrator of energy metabolism. Prog Brain Res. 2006; 153:209-235. [PubMed: 16876577]

Lechan RM, Jackson IM. Immunohistochemical localization of thyrotropin-releasing hormone in the rat hypothalamus and pituitary. Endocrinology. 1982; 111(1):55-65. [PubMed: 6806077]

Lechan RM, Kakucska I. Feedback regulation of thyrotropin-releasing hormone gene expression by thyroid hormone in the hypothalamic paraventricular nucleus. Ciba Found Symp. 1992; 168:144158. discussion 158-164. [PubMed: 1425022]

Merchenthaler I, Liposits Z. Mapping of thyrotropin-releasing hormone (TRH) neuronal systems of rat forebrain projecting to the median eminence and the OVLT. Immunocytochemistry combined with retrograde labeling at the light and electron microscopic levels. Acta Biol Hung. 1994; 45(2-4): 361-374. [PubMed: 7725828]

Paxinos, G.; Franklin, KBJ. The mouse brain in stereotaxic coordinates. Academic Press; San Diego: 2001.

Paxinos, G.; Watson, C. The Rat Brain in Stereotaxic Coordinates. Academic Press; San Diego, CA: 1998.

Peeters R, Fekete C, Goncalves C, Legradi G, Tu HM, Harney JW, Bianco AC, Lechan RM, Larsen PR. Regional physiological adaptation of the central nervous system deiodinases to iodine deficiency. Am J Physiol Endocrinol Metab. 2001; 281(1):E54-61. [PubMed: 11404222]

Reichlin S. TRH: historical aspects. Ann N Y Acad Sci. 1989; 553:1-6. [PubMed: 2497667]

Segerson TP, Kauer J, Wolfe HC, Mobtaker H, Wu P, Jackson IM, Lechan RM. Thyroid hormone regulates TRH biosynthesis in the paraventricular nucleus of the rat hypothalamus. Science. 1987; 238(4823):78-80. [PubMed: 3116669]

Simmons DM, Swanson LW. Comparison of the spatial distribution of seven types of neuroendocrine neurons in the rat paraventricular nucleus: toward a global 3D model. J Comp Neurol. 2009; 516(5):423-441. [PubMed: 19655400]

Swanson LW, Kuypers HG. The paraventricular nucleus of the hypothalamus: cytoarchitectonic subdivisions and organization of projections to the pituitary, dorsal vagal complex, and spinal cord as demonstrated by retrograde fluorescence double-labeling methods. J Comp Neurol. 1980; 194(3):555-570. [PubMed: 7451682]

Thim L, Nielsen PF, Judge ME, Andersen AS, Diers I, Egel-Mitani M, Hastrup S. Purification and characterisation of a new hypothalamic satiety peptide, cocaine and amphetamine regulated transcript (CART), produced in yeast. FEBS Lett. 1998; 428(3):263-268. [PubMed: 9654146] 
Vrang N, Larsen PJ, Clausen JT, Kristensen P. Neurochemical characterization of hypothalamic cocaine- amphetamine-regulated transcript neurons. J Neurosci. 1999; 19(10):RC5. [PubMed: 10234051]

Weindl, A. Neuroendocrine aspects of circumventricular organs.. In: Ganong, WF.; Martini, L., editors. Frontiers of Neuroendocrinology. Oxford U. Press; New York: 1973. p. 3-31.

Wittmann G, Füzesi F, Liposits Z, Lechan RM, Fekete C. Distribution and axonal projections of neurons co-expressing thyrotropin-releasing hormone and urocortin 3 in the rat brain. J Comp Neurol. 2009 
Figure 1.

Illustration of the nomenclature used in the current paper to identify the parts of the mouse PVN. Borders of the parts of the mouse PVN are labeled on images of Nissl-stained preparations. A-C represents three anterior-posterior levels of the PVN. III, Third ventricle; A, anterior part; $\mathrm{C}$, compact part; $\mathrm{M}$, midlevel medial part; $\mathrm{P}$, periventricular zone; PO, posterior part; Scale bar $=100 \mu \mathrm{m}$ 


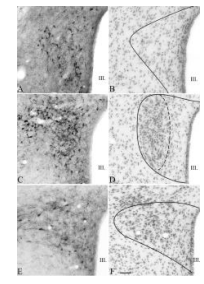

Figure 2.

Distribution of TRH neurons in the PVN of mice. Low magnification images (A, C, E) illustrate TRH-IR neurons at three, antero-posterior levels of the PVN. The borders of the PVN and the localization of the compact part are illustrated on neighboring cresyl-violet stained sections (B, D, F). Scale bar $=50 \mu \mathrm{m}$ 

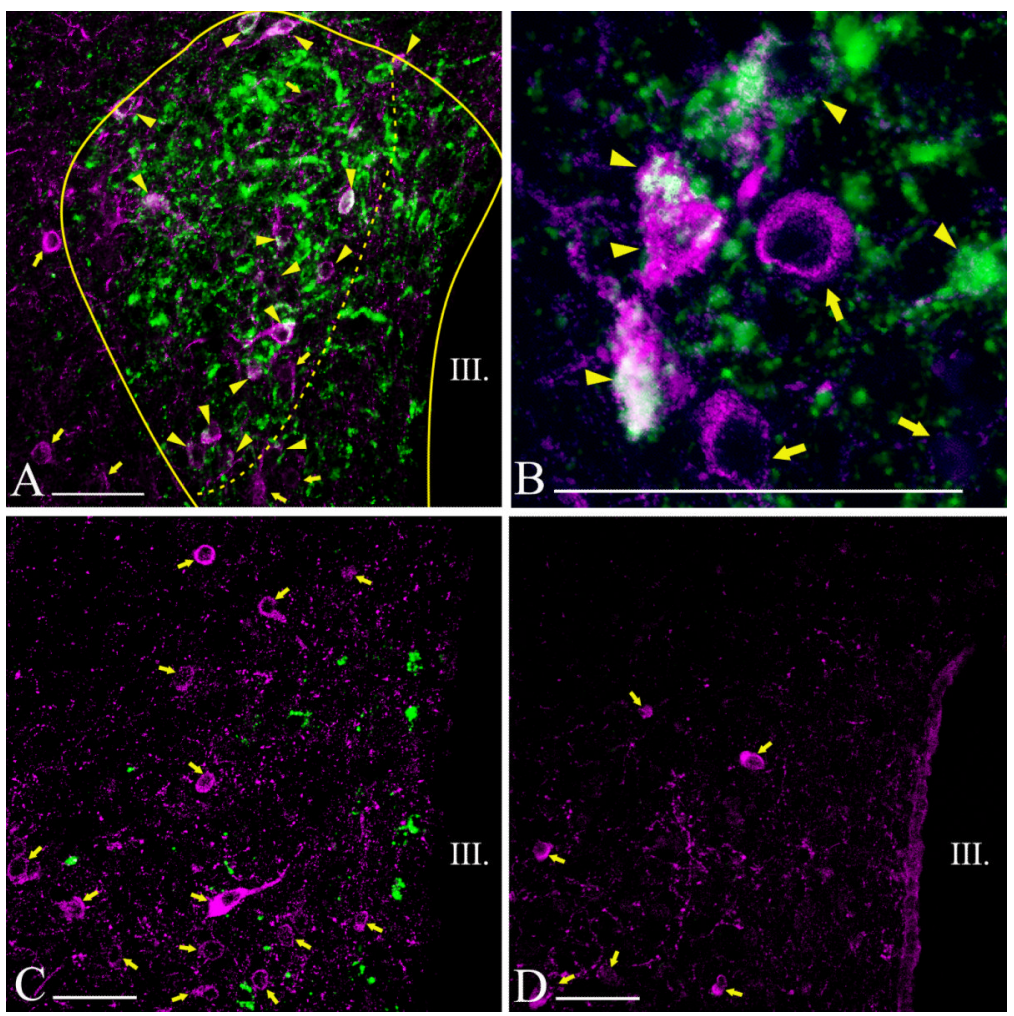

Figure 3.

Distribution of hypophysiotropic TRH neurons in the PVN of mice. The hypophysiotropic TRH neurons containing both TRH- (magenta) and Fluoro-Gold-immunoreactivity (green) can be observed at the mid level of PVN (A, B). Arrowheads point to double-labeled neurons, while arrows point to single-labeled non-hypophysiotropic TRH neurons. Most of the hypophysiotropic TRH neurons are located in the compact part demarcated by a broken line (A). High magnification image (B) illustrates the Fluoro-Gold (green) immunoreactivity in the TRH neurons (magenta) in the compact part of the PVN. Fluoro-Gold-

immunoreactivity was absent from TRH neurons in the anterior $(\mathrm{C})$ and posterior parts of the PVN (D). Each image represents single optical slices. The thickness of optical slice is 1 $\mu \mathrm{m}$ on B-D and $2 \mu \mathrm{m}$ on A. III, third ventricle; Scale bars on A-D $=50 \mu \mathrm{m}$. 


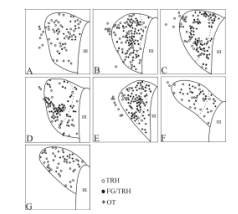

Figure 4.

Schematic drawings illustrate the distribution of hypophysiotropic TRH and OT neurons at different anterio-posterior levels of the PVN. Open circles denote single-labeled TRH neurons; filled circles denote double-labeled TRH/FG neurons; crosses denote OT neurons. The borders of the compact part are labeled with broken lines. 

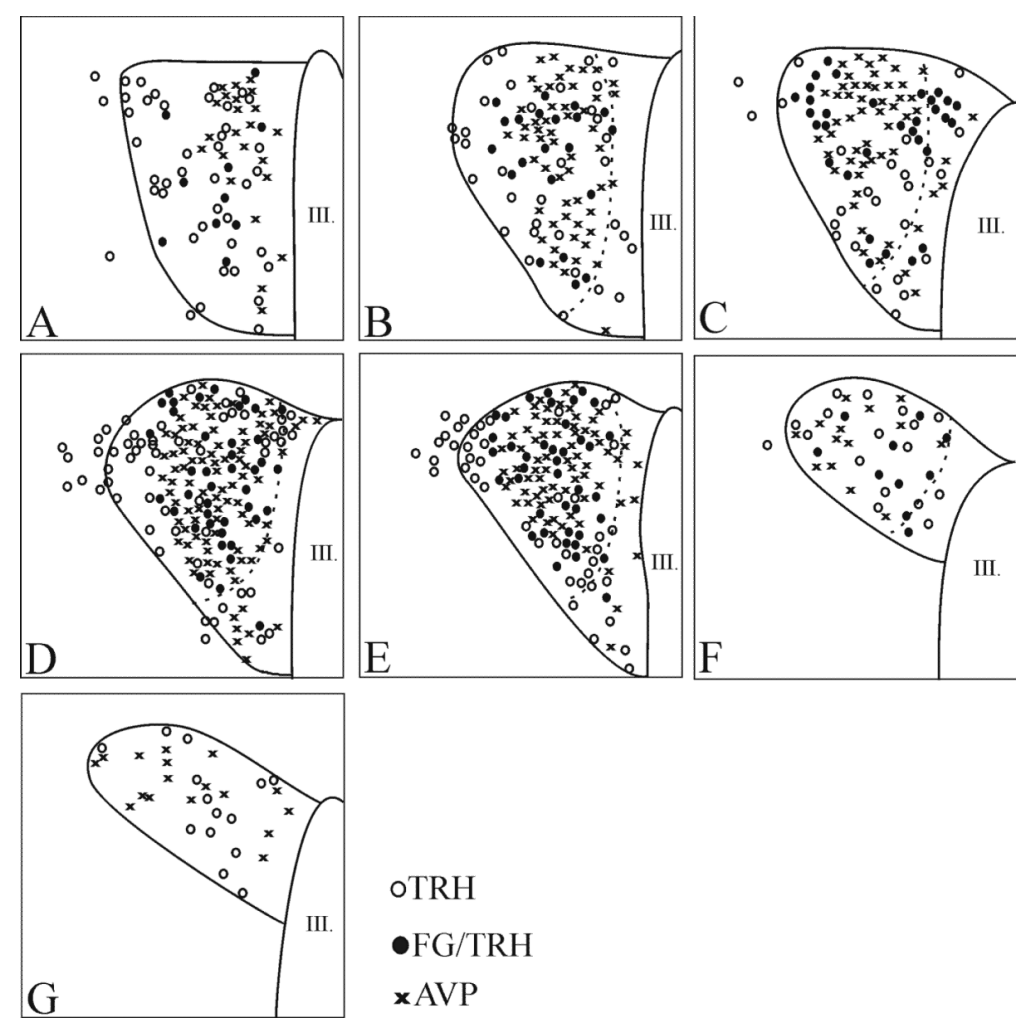

Figure 5.

Schematic drawings illustrate the distribution of hypophysiotropic TRH and AVP neurons at different antero-posterior levels of the PVN. Open circles denote single-labeled TRH neurons; filled circles denote double-labeled TRH/FG neurons; crosses denote AVP neurons. The borders of the compact part are labeled with broken lines. 

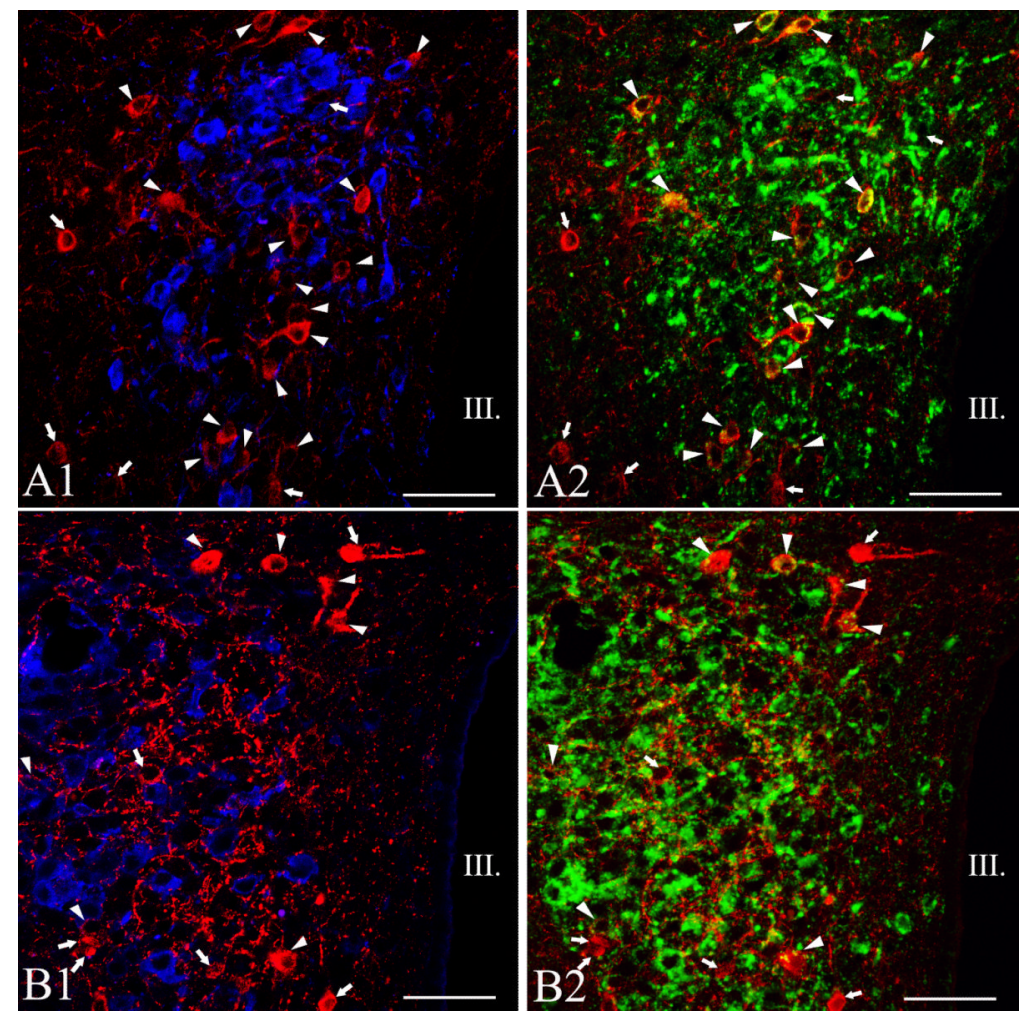

Figure 6.

Simultaneous localization of TRH with oxytocin (OT) and vasopressin (AVP) in the PVN of mice. Medium-magnification confocal images illustrate the distribution of the TRH-(red), AVP- (blue, A1), OT- (blue, B2) and Fluoro-Gold-IR (green) cells at the mid level of the PVN. A1-2 or B1-2 images represents the same field. Note that TRH is not colocalized with the magnocellular peptides. Arrows point to single-labeled TRH neurons, while arrowheads label the hypophysiotropic TRH neurons. Each image represents $1 \mu \mathrm{m}$ thick optical slices. III, third ventricle, Scale bar $=50 \mu \mathrm{m}$. 


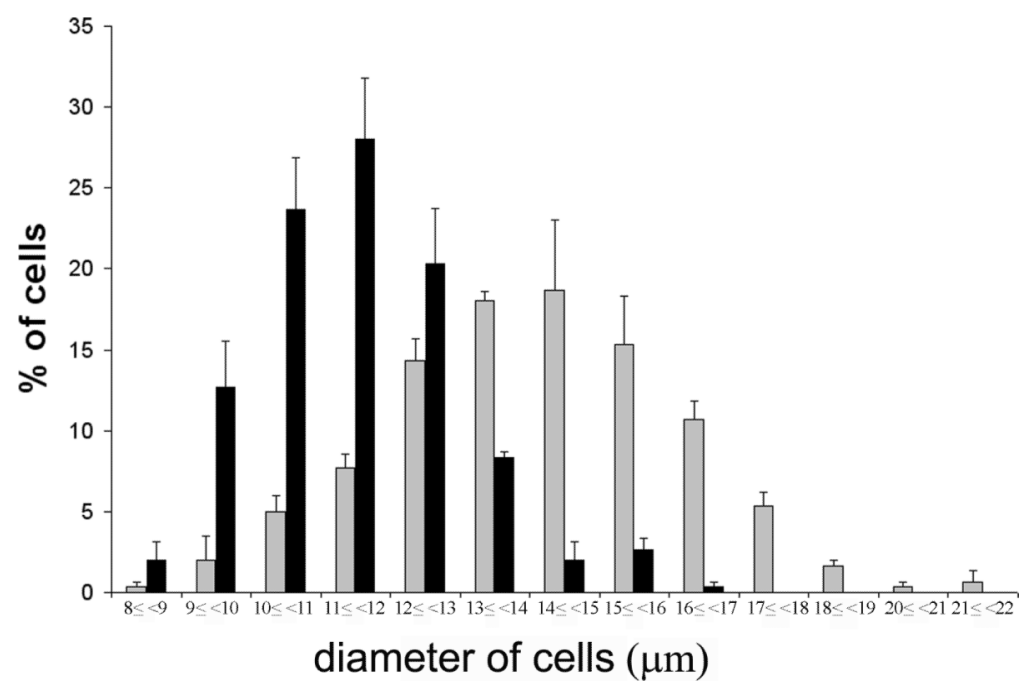

Figure 7.

Distribution of cell size in the midlevel medial part of the PVN (black bars) and in the compact part of the PVN (gray bars). 

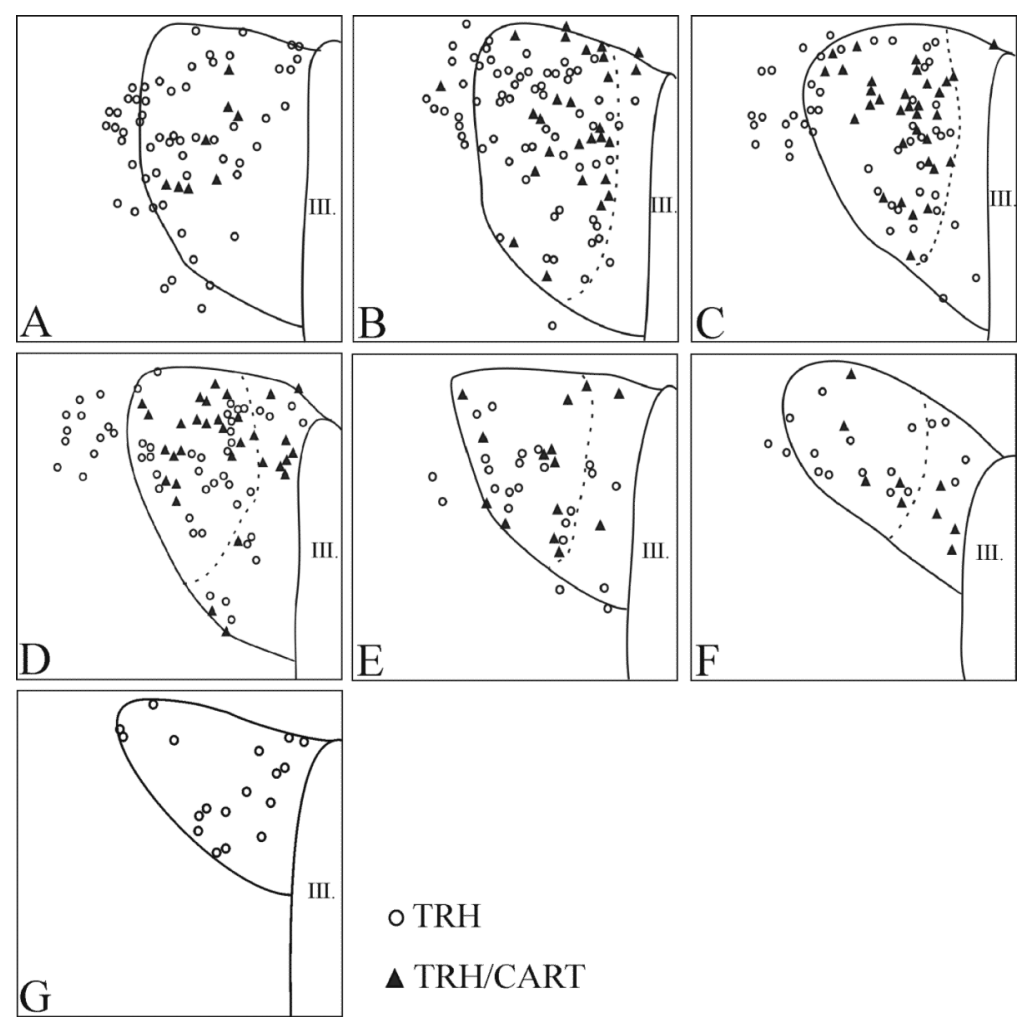

Figure 8.

Schematic drawings illustrating colocalization of TRH and CART at different anterioposterior levels of the PVN. Open circles represent single-labeled TRH neurons; filled triangles indicate double-labeled TRH/CART neurons. 

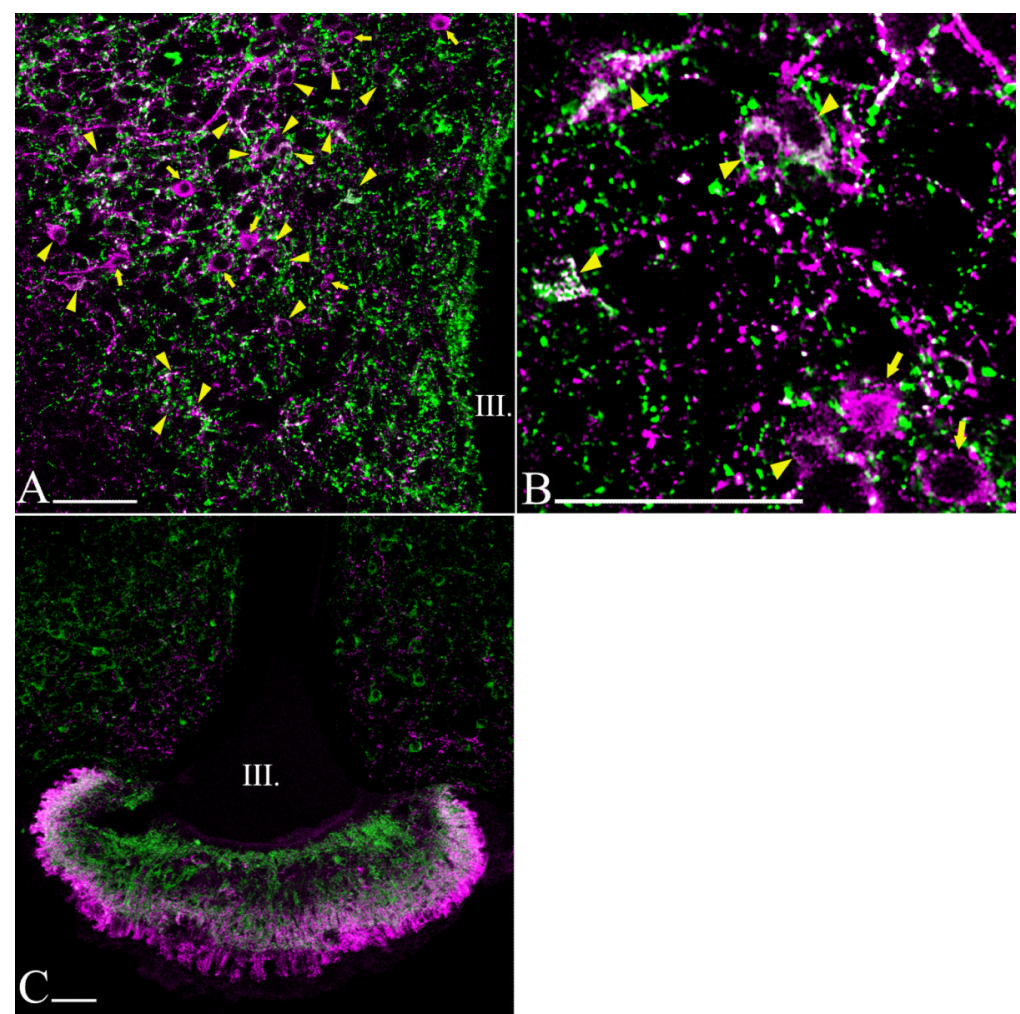

Figure 9.

Colocalization of TRH with CART in the PVN of mice. Low (A) and high (B) power magnification images show colocalization of TRH (magenta) and CART (green) in the compact part of the PVN. Arrowheads indicate the double-labeled neurons, while arrows point to single-labeled TRH neurons. Co-localization of TRH and CART is also detected in the axonterminals of median eminence $(C)$. The thickness of optical slice is $1 \mu \mathrm{m}$ on B and 2 $\mu \mathrm{m}$ on A and C. III, third ventricle; Scale bar $=50 \mu \mathrm{m}$. 


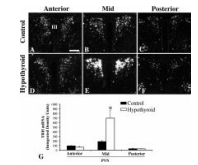

Figure 10.

Darkfield photomicrographs showing TRH mRNA expression in the anterior, mid-level and posterior regions of the PVN in control (A-C) and hypothyroid (D-F) animals. Note dramatic increase $(\mathrm{P}<0.001)$ in silver grains only in the mid-level neurons in the hypothyroid animals. (G) Computerized image analysis of silver grains accumulating over neurons in each subregion of the PVN in control and hypothyroid animals. III < third ventricle. *, $\mathrm{P}<0.001$. 
Table 1

Description of the used antibodies.

\begin{tabular}{|l|l|l|l|}
\hline Antigen & Immunogen & Description of the antibody & Dilution used \\
\hline Thyrothropin-Releasin Hormone (TRH) & $\begin{array}{l}\text { TRH-acrolein-bovine serum albumin } \\
\text { (BSA) conjugate }\end{array}$ & $\begin{array}{l}\text { Generated in our laboratory, } \\
\text { affinity purified sheep polyclonal } \\
\text { antibody, \#08W2 }\end{array}$ & $1: 4000$ \\
\hline $\begin{array}{l}\text { Cocaine- and Amphetamine-Regulated } \\
\text { Transcript (CART) }\end{array}$ & $\begin{array}{l}\text { Purified recombinant rat CART } \\
\text { usi-89)-conjugated to ovalbumin } \\
\text { using carbodiimide }\end{array}$ & $\begin{array}{l}\text { Dr. Jes Thorn Clausen (Novo } \\
\text { Nordisk A/S, Bagsvaerd, } \\
\text { Denmark), mouse monoclonal } \\
\text { antibody, Ca\&-1F4.D4 }\end{array}$ & $1: 1500$ \\
\hline Oxytocin-neurophysin (OT-NP) & Purified rat OT-neurophysin & $\begin{array}{l}\text { Dr. Sharon Key (NIH, Bethesda, } \\
\text { MD, US), monoclonal mouse } \\
\text { antibody, \#PS-38 }\end{array}$ & $1: 500$ \\
\hline Vasopressin-neurophysin (AVP-NP) & Purified rat AVP-neurophysin & $\begin{array}{l}\text { Dr H.Gainer (NIH, Bethesda, MD, } \\
\text { US), mouse monoclonal antibody, } \\
\text { \#PS-41 }\end{array}$ & $1: 500$ \\
\hline Fluoro-Gold (FG) & Fluoro-Gold & $\begin{array}{l}\text { Chemicon International Inc., rabbit } \\
\text { polyclonal antiserum, \#AB153 }\end{array}$ & $1: 24000$ \\
\hline
\end{tabular}

